\title{
2017 recommendations of the Brazilian Society of Rheumatology for the pharmacological treatment of rheumatoid arthritis
}

Licia Maria Henrique da Mota ${ }^{1,16^{*}}$, Adriana Maria Kakehasi ${ }^{2}$, Ana Paula Monteiro Gomides ${ }^{1,3}$, Angela Luzia Branco Pinto Duarte ${ }^{4}$, Bóris Afonso Cruz ${ }^{5}$, Claiton Viegas Brenol ${ }^{6}$, Cleandro Pires de Albuquerque ${ }^{7}$, Geraldo da Rocha Castelar Pinheiro ${ }^{8}$, leda Maria Magalhães Laurindo ${ }^{9}$, Ivanio Alves Pereira ${ }^{10}$, Manoel Barros Bertolo ${ }^{11}$, Mariana Peixoto Guimarães Ubirajara Silva de Souza ${ }^{12}$, Max Vitor Carioca de Freitas ${ }^{13}$, Paulo Louzada-Júnior ${ }^{14}$, Ricardo Machado Xavier ${ }^{6}$ and Rina Dalva Neubarth Giorgi ${ }^{15}$

\begin{abstract}
The objective of this document is to provide a comprehensive update of the recommendations of Brazilian Society of Rheumatology on drug treatment of rheumatoid arthritis (RA), based on a systematic literature review and on the opinion of a panel of rheumatologists. Four general principles and eleven recommendations were approved. General principles: RA treatment should (1) preferably consist of a multidisciplinary approach coordinated by a rheumatologist, (2) include counseling on lifestyle habits, strict control of comorbidities, and updates of the vaccination record, (3) be based on decisions shared by the patient and the physician after clarification about the disease and the available therapeutic options; (4) the goal is sustained clinical remission or, when this is not feasible, low disease activity. Recommendations: (1) the first line of treatment should be a CSDMARD, started as soon as the diagnosis of RA is established; (2) methotrexate (MTX) is the first-choice csDMARD; (3) the combination of two or more cSDMARDs, including MTX, may be used as the first line of treatment; (4) after failure of first-line therapy with MTX, the therapeutic strategies include combining MTX with another cSDMARD (leflunomide), with two csDMARDs (hydroxychloroquine and sulfasalazine), or switching MTX for another csDMARD (leflunomide or sulfasalazine) alone; (5) after failure of two schemes with csDMARDs, a bDMARD may be preferably used or, alternatively a tsDMARD, preferably combined, in both cases, with a csDMARD; (6) the different bDMARDs in combination with MTX have similar efficacy, and therefore, the therapeutic choice should take into account the peculiarities of each drug in terms of safety and cost; (7) the combination of a bDMARD and MTX is preferred over the use of a bDMARD alone; (8) in case of failure of an initial treatment scheme with a bDMARD, a scheme with another bDMARD can be used; in cases of failure with a TNFi, a second bDMARD of the same class or with another mechanism of action is effective and safe; (9) tofacitinib can be used to treat RA after failure of bDMARD; (10) corticosteroids, preferably at low doses for the shortest possible time, should be considered during periods of disease activity, and the risk-benefit ratio should also be considered; (11) reducing or spacing out bDMARD doses is possible in patients in sustained remission.
\end{abstract}

\footnotetext{
* Correspondence: liciamhmota@gmail.com

${ }^{1}$ Programa de Pós-graduação em Ciências Médicas, Faculdade de Medicina-

Universidade de Brasília; Serviço de Reumatologia, Hospital Universitário de

Brasília, Universidade de Brasilia, Brasília, Brazil

${ }^{16}$ Rheos, Centro Médico Lúcio Costa, SGAS 610, bloco 1, salas T50- T51, L2

Sul, Asa Sul, Brasília, DF 70200700, Brazil

Full list of author information is available at the end of the article
}

(c) The Author(s). 2018 Open Access This article is distributed under the terms of the Creative Commons Attribution 4.0 International License (http://creativecommons.org/licenses/by/4.0/), which permits unrestricted use, distribution, and

reproduction in any medium, provided you give appropriate credit to the original author(s) and the source, provide a link to the Creative Commons license, and indicate if changes were made. The Creative Commons Public Domain Dedication waiver (http://creativecommons.org/publicdomain/zero/1.0/) applies to the data made available in this article, unless otherwise stated. 


\section{Introduction}

Rheumatoid arthritis (RA) is a systemic inflammatory autoimmune disease characterized primarily by the involvement of the synovial membrane of peripheral joints. The estimated prevalence of RA in the total population is $0.5-1.0 \%$, and the incidence is higher in the 30-50-yearold age group and among women $[1,2]$. In Brazil, a study conducted in Minas Gerais found a prevalence of $0.46 \%$ [3]. The past few decades have introduced a substantial increase in the number of RA treatments due to advances in knowledge concerning the pathophysiological mechanisms of the disease and the development of new drugs. Moreover, new monitoring and treatment strategies have been implemented, including comprehensive disease control and early intervention, during the onset of symptoms [4]. In 2012 and 2013, the RA Committee of the Brazilian Society of Rheumatology (Sociedade Brasileira de Reumatologia-SBR) published recommendations on RA diagnosis and treatment in Brazil to provide support to Brazilian rheumatologists, based upon scientific evidence combined with the experience of a panel of specialists, while safeguarding the necessary autonomy of physicians in choosing among the available therapeutic strategies [5-8]. In 2015, the recommendations were updated to include the use of target-specific synthetic disease-modifying antirheumatic drugs [9].

The objective of the current document is to provide a comprehensive update of the recommendations of SBR on drug treatment of RA in Brazil considering the advances accrued since the last revision. The scope of this work is limited to adult disease because juvenile idiopathic arthritis requires distinct and specific approaches.

\section{Methods}

The present recommendations were based on a Systematic Literature Review (SLR) and on the opinion of a panel of rheumatologists specialized in RA. In September 2016, the RA Committee met to develop questions to guide the SLR based on real-life scenarios, and these questions were improved by multiple subsequent rounds of online discussion. At the end of the interactive process, ten questions considered essential for the preparation of the recommendations were selected (Table 1). Furthermore, four general principles that should guide the entire RA treatment based on concepts widely established in the literature were formulated.

An SLR was undertaken to answer the proposed questions. Randomized clinical trials and systematic reviews of randomized clinical trials were considered eligible primarily, but controlled observational studies were also considered acceptable when interventional studies with those designs were not available. The MEDLINE, EMBASE, and SCOPUS databases were searched using specific search strategies (Table 2). In addition, the references of the
Table 1 Questions based on clinical scenarios, selected by the rheumatoid arthritis committee of the brazilian society of rheumatology to guide the development of the recommendations

Questions about possible clinical scenarios for treating rheumatoid arthritis in Brazil, considering safety, effectiveness, and cost.

Question 1: Should the first line of treatment be csDMARD (methotrexate, hydroxychloroquine, leflunomide, or sulfasalazine), tsDMARD (tofacitinib), or bDMARD (adalimumab, certolizumab, etanercept, infliximab, golimumab, abatacept, rituximab, or tocilizumab)?

Question 2: Is there evidence that a particular csDMARD is more effective than other csDMARDs?

Question 3: Is there evidence that the use of combination therapy with two or more csDMARDs is more effective than csDMARD monotherapy as the first line of treatment?

Question 4: Is there evidence that after failure of a csDMARD monotherapy as the first line of treatment, the best option is to switch to a second monotherapy regimen rather than using combination therapy with two or more csDMARDs?

Question 5: Is there evidence that a particular TNFi (adalimumab, certolizumab, etanercept, golimumab, or infliximab) or non-TNFi (abatacept, rituximab, or tocilizumab) bDMARD is more effective than other biological agents?

Question 6: Is there evidence that bDMARD (adalimumab, certolizumab, etanercept, golimumab, infliximab, abatacept, rituximab, or tocilizumab) combined with methotrexate is more effective than bDMARD monotherapy?

Question 7: In the case of failure of a first bDMARD scheme, is there evidence that a second bDMARD scheme is effective?

Question 8: Is there evidence that tsDMARD (tofacitinib) is more effective than bDMARD (adalimumab, certolizumab, etanercept, golimumab, infliximab, abatacept, rituximab, or tocilizumab)?

Question 9: Is there evidence that oral, parenteral, or intra-articular use of corticosteroids improves prognosis when combined with DMARD?

Question 10: Is there evidence that it is possible to reduce the dose or increase the dose intervals for bDMARD in patients in remission?

csDMARD conventional synthetic disease-modifying drugs - methotrexate, leflunomide, sulfasalazine and antimalarials (hydroxychloroquine and chloroquine) tsDMARD: synthetic target-specific disease-modifying drugs - tofacitinib bDMARD: biological disease-modifying drugs - tumor necrosis factor inhibitors/TNFi (adalimumab, certolizumab, etanercept, golimumab, infliximab), T-lymphocyte costimulation modulator (abatacept), anti-CD20 (rituximab), and IL-6 receptor blocker (tocilizumab)

selected studies, as well as relevant publications in the area, and the annals of congresses most relevant to the specialty were also searched. The search included the period from 2006 to October 2016 without language restrictions and was updated monthly until March 2017.

The studies were selected using the Covidence system (www.covidence.org). Two independent researchers analyzed the retrieved publications based on the titles and abstracts. Cases of disagreement were resolved by consensus. The risk of bias in clinical trials was assessed using the tool proposed by the Cochrane Collaboration [10]. Systematic reviews were evaluated using the AMSTAR tool [11]. The quality of evidence for each outcome (high, moderate, low, or very low) was evaluated using the GRADE tool (https://gradepro.org) [12]. The risk of publication bias was assessed by consulting the protocols of the clinical trials registered in ClinicalTrials.gov (https://clinicaltrials.gov) 
Table 2 Search strategies used in the MEDLINE, EMBASE and SCOPUS databases for obtaining evidence on drug therapies for rheumatoid arthritis

\begin{tabular}{ll}
\hline Database & Strategy \\
\hline MEDLINE (via PubMed) & $(((($ meta analysis[ptyp] OR meta-analysis[tiab] OR meta-analysis[mh] OR (systematic[tiab] AND review[tiab]) NOT \\
& ((case[ti] AND report[ti]) OR editorial[ptyp] OR comment[ptyp] OR letter[ptyp] OR newspaper article [ptyp])) OR \\
& (randomized controlled trial[Publication Type] OR (randomized[Title/Abstract] AND controlled[Title/Abstract] AND \\
& trial[Title/Abstract])))) AND ((arthritis, rheumatoid[mh:noexp]) or (rheumatoid arthriti*[text word])) Filters: Publication \\
& date from 2006/01/01 \\
& 'rheumatoid arthritis'/mj AND ([cochrane review]/lim OR [systematic review]/lim OR [controlled clinical trial]/lim \\
& OR [randomized controlled trial]/lim OR [meta analysis]/lim) AND [2006-2016]/py NOT [medline]/lim \\
EMBASE & TITLE-ABS-KEY(rheumatoid arthritis) AND((TITLE-ABS-KEY(randomized) AND TITLE-ABS-KEY(controlled) AND TITLE- \\
& ABS-KEY(trial)) OR (TITLE-ABS-KEY(meta-analysis) OR (TITLE-ABS-KEY(systematic) AND TITLE-ABS-KEY(review)))) AND \\
SCOPUS & (PUBYEAR > 2006) AND NOT (INDEX(medline) Or INDEX(embase)) \\
&
\end{tabular}

and WHO International Clinical Trials Registry Platform (http://www.who.int/ictrp/en) when available and by asymmetry analysis of funnel plots.

The methodological details of the SLR that supported the present recommendations and the expanded results, together with the rationale of the answers to the formulated questions, will be available as Additional file 1. In the present document, a predominantly clinical approach was adopted, in which the SLR findings were summarized in a technically accessible language as the basis for the recommendations.

Based on the results of the SLR, the RA Committee met in June and August 2017 in São Paulo and Belo Horizonte to establish the level of agreement with each general principle and recommendation according to the methodology described below. After presenting each statement, a secret ballot was held, in which the participants could agree or disagree with the general proposition of each statement. In cases of agreement by at least $70 \%$ of the participants present, a new vote was conducted to assess the level of agreement with the text using a numerical scale from 0 ("completely disagree") to 10 ("completely agree"). The general principles and recommendations that did not reach a minimum rate of agreement of $70 \%$ initially were subjected to repeated steps of reformulation and voting until this rate was reached, and the level of agreement was then determined.

This process resulted in the approval of four general principles and eleven recommendations for drug treatment of RA in Brazil, which are presented in Table 3 and discussed below. This document also includes a section on therapeutic strategies, and this section serves as the basis for the understanding and practical application of the recommendations. The therapeutic strategies were graphically summarized into the new flowchart for drug treatment of RA in Brazil (Fig. 1).

The following abbreviations and nomenclature for disease-modifying antirheumatic drugs (DMARDs) were used in this document:
csDMARD: conventional synthetic disease-modifying antirheumatic drugs - methotrexate, leflunomide, sulfasalazine, and antimalarial drugs (hydroxychloroquine and chloroquine).

tsDMARD: synthetic target-specific disease-modifying antirheumatic drug - tofacitinib.

bDMARD: biological disease-modifying antirheumatic drugs - tumor necrosis factor inhibitors/TNFi (adalimumab, certolizumab, etanercept, golimumab, infliximab), T-lymphocyte co-stimulation modulator (abatacept) , anti-CD20 (rituximab), and IL-6 receptor blocker (tocilizumab).

boDMARD: original biological disease-modifying antirheumatic drugs.

bsDMARD: biosimilar biological disease-modifying antirheumatic drugs.

\section{General principles}

General principle 1: Treatment of patients with RA should preferably consist of a multidisciplinary approach coordinated by a rheumatologist. (level of agreement: 9.87) Patients with RA should be preferably monitored by a multidisciplinary team, including a physician, physiotherapist, occupational therapist, psychologist, and nutritionist, among others. The rheumatologist, as a specialist in RA, should be responsible for coordinating the treatment.

General principle 2: Treatment of patients with RA should include counseling on lifestyle habits, strict control of comorbidities, and updates of the vaccination record. (level of agreement: 10)

Smoking, excessive intake of alcoholic beverages, obesity, and a sedentary lifestyle should be strongly discouraged. The active search and appropriate management of comorbidities, particularly systemic arterial hypertension, diabetes mellitus, dyslipidemia, and osteoporosis, are part of the care of patients with RA. The patient's vaccination record should be updated 
Table 3 General principles and recommendations of the Brazilian Society of Rheumatology for pharmacological treatment of rheumatoid arthritis in Brazil

General principles

General principle 1: Treatment of patients with RA should preferably consist of a multidisciplinary approach coordinated by a rheumatologist. Level of agreement: 9.87

General principle 2: RA treatment should include counseling on lifestyle habits, strict control of comorbidities, and updates of the vaccination record.

Level of agreement: 10

General principle 3: RA treatment should be based on decisions shared by the patient and physician after clarification about the disease and the available therapeutic options.

Level of agreement: 9.93

General Principle 4: The goal of RA treatment is sustained clinical remission or, when this is not feasible, low disease activity.

Level of agreement: 9.87

Recommendations for drug treatment of RA

Recommendation 1: The first line of treatment should be a cSDMARD, started as soon as the diagnosis of RA is established.

Level of agreement: 9.93

Recommendation 2: Methotrexate is the first-choice csDMARD. Level of agreement: 10

Recommendation 3: Combination of two or more csDMARDs, including methotrexate, may be used as the first line of treatment. Level of agreement: 9.62

Recommendation 4: After failure of first-line therapy with MTX, the therapeutic strategies include combining MTX with another csDMARD (leflunomide), with two csDMARDs (hydroxychloroquine and sulfasalazine), or switching MTX for another csDMARD (leflunomide or sulfasalazine) alone.

Level of agreement: 9.12

Recommendation 5: After failure of two schemes with CSDMARD, a bDMARD may be preferably used or, alternatively, a tsDMARD, preferably combined, in both cases, with a csDMARD.

Level of agreement: 9.5

Recommendation 6: The different bDMARDs in combination with MTX have similar efficacy, and therefore, the therapeutic choice should take into account the peculiarities of each drug in terms of safety and cost.

Level of agreement: 9.31

Recommendation 7: The combination of bDMARD and methotrexate is preferred over the use of bDMARD alone.

Level of agreement: 9.87

Recommendation 8: In case of failure of an initial treatment scheme with bDMARD, a scheme with another bDMARD can be used. In cases of failure with a TNFi, a second bDMARD of the same class or with another mechanism of action is effective and safe.

Level of agreement: 9.37

Recommendation 9: Tofacitinib can be used to treat RA after failure of bDMARD.

Level of agreement: 9.81

Recommendation 10: Corticosteroids, preferably at low doses for the shortest possible time, should be considered during periods of disease activity, and the risk-benefit ratio should also be considered. Level of agreement: 9.81

Recommendation 11: Reducing or spacing out bDMARD doses is possible in patients in sustained remission.

Level of agreement: 9.31
csDMARD: Conventional synthetic disease-modifying antirheumatic drugs (methotrexate, leflunomide, sulfasalazine) and antimalarials (hydroxychloroquine and chloroquine)

tsDMARD: Synthetic target-specific disease-modifying antirheumatic drugs - tofacitinib

bDMARD: biological disease-modifying drugs - tumor necrosis factor inhibitors/ TNFi (adalimumab, certolizumab, etanercept, golimumab, infliximab), T-lymphocyte costimulation modulator (abatacept), anti-CD20 (rituximab), and IL-6 receptor blocker (tocilizumab)

preferably before the initiation of treatment and kept updated during follow-up.

General principle 3: Treatment of patients with RA should be based on decisions that are shared by the patient and the physician after clarification about the disease and the available therapeutic options. (level of agreement: 9.93)

Patients with RA should be informed about the nature and prognosis of the disease. Moreover, patients should be informed about the available therapeutic options, their benefits, potential adverse effects, and costs.

General principle 4: The goal of RA treatment is sustained clinical remission or, when this is not feasible, low disease activity. (level of agreement: 9.83)

The rheumatologist and the patient should acknowledge that the goal of treatment is sustained clinical remission or, in cases where this is not feasible, low disease activity. In the long term, these outcomes are related to the best clinical, structural, and functional evolution [13-15].

Regular monitoring of clinical, laboratory, and imaging parameters is necessary to achieve this goal. In the initial stage of RA (the first 6 months of symptoms) and whenever the disease presents with significant inflammatory activity, follow-up should be performed monthly to allow dosage adjustment or changes in medication for disease management.

\section{Recommendations}

Recommendation 1: The first line of treatment should be a csDMARD started as soon as the diagnosis of RA is established. (level of agreement: 9.93)

The efficacy (ACR50 response) of methotrexate (MTX) monotherapy is similar to that of bDMARD monotherapy, except for tocilizumab, which was more effective than MTX [16-23].

Although monotherapy with tofacitinib has been shown more effective than with MTX, the limited availability of long-term safety data on the former requires caution and precludes its use as the first line of treatment, until more data become available [24].

In addition, the lower cost of csDMARD should be taken into account, although few cost-effectiveness 


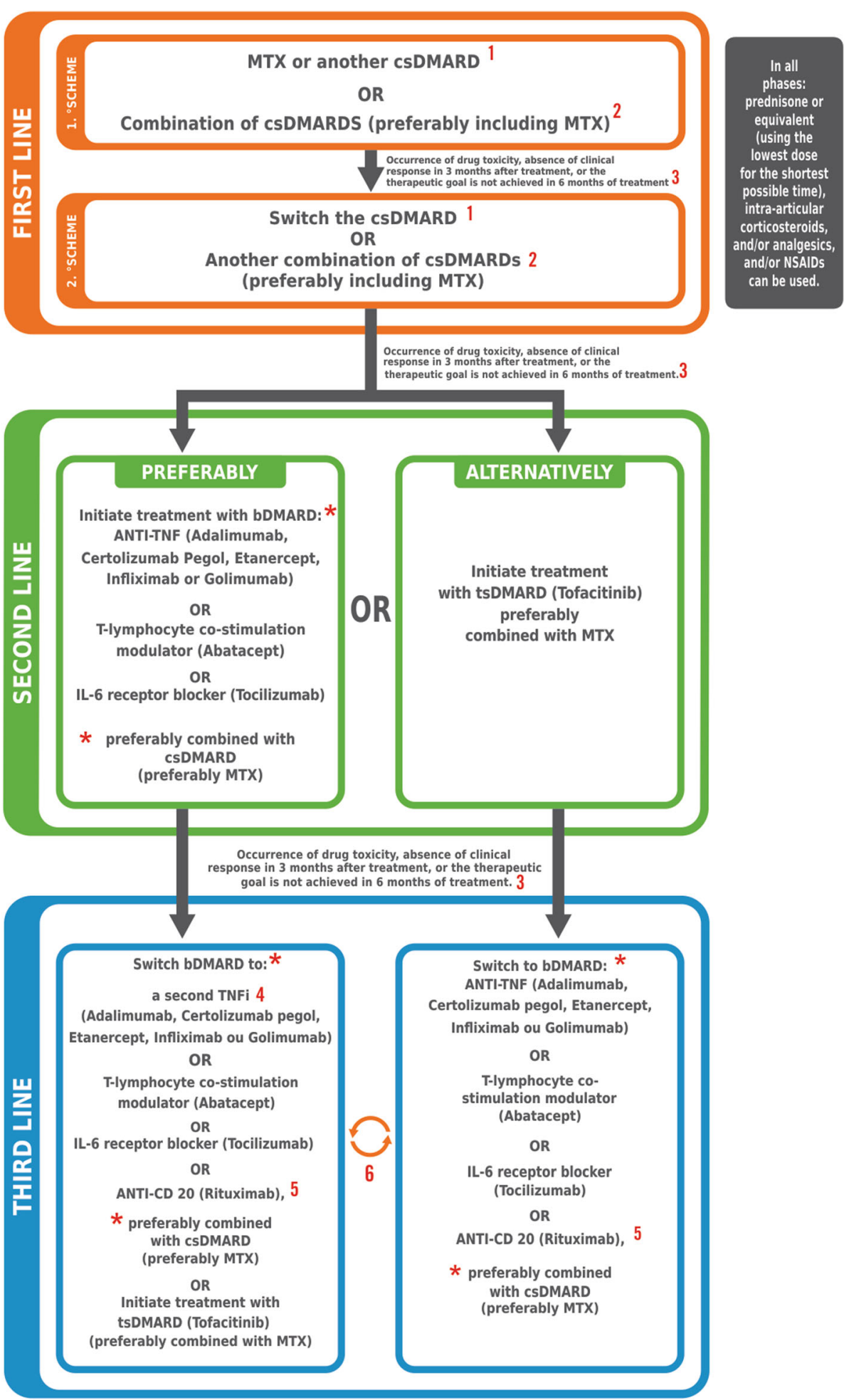

Fig. 1 (See legend on next page.) 
(See figure on previous page.)

Fig. 1 Flowchart - 2017 Recommendations of the Brazillan Society of Rheumatology for pharmacological treatment of rheumatoid arthritis. 1: Sulfasalazine or leflunomide may be used in cases of contraindication to MTX. Antimalarials (hydroxychloroquine or chloroquine) as monotherapy may be considered in cases of low probability of development of radiographic erosions. 2: The most used combinations in Brazil are MTX + antimalarials, MTX + leflunomide (with or without antimalarials), MTX + sulfasalazine (with or without antimalarials). 3: The goal of treatment is remission according to ACR/EULAR criteria or, in cases where this is not possible, low disease activity, as assessed by one of the composite disease activity indices defined in the 2011 SBR Consensus (5). 4: The use of a third TNFi after failure of two TNFi drugs is not recommended. 5: In Brazil, rituximab is recommended in combination with methotrexate for patients with a poor response or intolerance to one or more TNFi drugs. 6: In case of failure or toxicity to a drug used in the third line of treatment, the next step is switching to another drug (bDMARD or tsDMARD) with the same level of complexity and that has not been used previously

studies have evaluated the use of csDMARD as the first line of treatment. The quality of evidence for this recommendation is low to moderate.

\section{Recommendation 2: Methotrexate is the first-choice csDMARD. (level of agreement: 10)}

There were no significant differences in the efficacy of csDMARD for most of the relevant outcomes (ACR50 and ACR70 response, number of painful and swollen joints, disease activity, pain, and functional capacity moderate evidence) [25-36].

Compared with MTX, leflunomide causes more adverse events (discontinuation of treatment, rashes, and systemic arterial hypertension- high evidence) [30-33].

However, MTX has the highest risk of hepatic and pulmonary adverse events (low to very low evidence) [37, 38].

Subcutaneous MTX was shown to be superior to oral MTX in ACR70 and pain control, with fewer gastrointestinal adverse reactions (moderate evidence) [39].

MTX remains the first-choice drug for the RA treatment because of its efficacy and safety, possibility of individualizing the dose and route of administration, and relatively low cost $[30,40]$.

\section{Recommendation 3: Combination of two or more} csDMARD, including MTX, may be used as the first line of treatment. (level of agreement: 9.62)

As a first line of treatment, among the possible combinations of csDMARD, triple therapy with MTX + sulfasalazine + hydroxychloroquine, and MTX + leflunomide, both schemes compared with MTX monotherapy, showed an improved ACR response (high to moderate evidence) $[25,41,42]$. However, the cost of combination therapy is higher [43], and there is no evidence of a clinically significant difference between MTX alone and the combination of DMARDs (MTX + leflunomide, and triple therapy) in other disease activity indices [25, 42, 44-47] (moderate to low evidence), radiographic progression [41, 42, 48] (moderate to low evidence), and therapeutic safety $[25,41,47,49]$ (moderate to low evidence).
Recommendation 4: After failure of first-line therapy with MTX, therapeutic strategies include combining MTX with another csDMARD (leflunomide), with two csDMARDs (hydroxychloroquine and sulfasalazine), or switching MTX for another csDMARD (leflunomide or sulfasalazine)

alone. (level of agreement: 9.12)

After failure of MTX as the first line of treatment, leflunomide (20 mg/day, without a loading dose) or sulfasalazine (with an increase in dosage to $3 \mathrm{~g} /$ day) are monotherapy alternatives [31, 50, 51]. Both the combination of MTX with leflunomide or with hydroxychloroquine + sulfasalazine provided better ACR50 response rates compared with MTX alone (moderate evidence), with no significant difference in radiographic progression and discontinuation of treatment due to adverse events (low evidence) [50]. The combination of sulfasalazine with MTX (without hydroxychloroquine) compared to MTX alone did not show an incremental benefit (low evidence) [41].

After failure of leflunomide, replacement with sulfasalazine or the combination of sulfasalazine and leflunomide had no additional benefit in ACR50 response, pain, quality of life, and treatment dropout (moderate evidence) [52].

After failure of sulfasalazine, the inclusion of MTX did not provide additional benefits in ACR20, ACR50, and ACR70 (moderate evidence), although an improvement of the disease activity score (DAS) with the combination of csDMARDs was observed after 18 months of treatment [53].

\section{Recommendation 5: After failure of two schemes with} CSDMARD, a bDMARD may be preferably used or, alternatively, a tsDMARD, preferably combined, in both cases, with a csDMARD. (level of agreement: 9.5)

The combination of bDMARD and MTX produces higher ACR20, ACR50, and ACR70 response rates after 6 months of treatment compared with MTX monotherapy [54]. Higher ACR70 response rates at 6 to 12 months of treatment were also observed with the combination of bDMARD and csDMARD (not necessarily MTX) versus csDMARD alone [18]. The addition of bDMARD in cases of a poor response to csDMARD was effective 
[24]. In cases of poor response to a csDMARD, the addition of a bDMARD was effective.

The tsDMARD tofacitinib in monotherapy or in combination with MTX was effective and safe in patients with a poor response to csDMARD, with improvement in disease activity and physical function and a reduction of radiographic progression $[55,56]$.

However, long-term safety and real-life data are not yet available for tsDMARD, and thus, a preference for bDMARD over tofacitinib after csDMARD failure has been proposed.

Recommendation 6: The different bDMARDs in combination with MTX have similar efficacy, and therefore, the therapeutic choice should take into account the peculiarities of each drug in terms of safety and cost. (level of agreement: 9.31)

The available bDMARDs have similar levels of effectiveness for the number of painful or swollen joints, disease activity, quality of life, functional capacity, and pain control [16, 57-62]. However, total annual costs of treatment vary among the different bDMARDs and these differences need to be taken into consideration at the time of drug selection (low to moderate evidence) [63]. All bDMARDs have consistently demonstrated superior efficacy when used in combination with MTX compared with MTX monotherapy [24, 40].

Patients using bDMARDs compared with those using csDMARDs have an increased risk of severe infections [64-68]. In general, different bDMARDs have similar levels of safety. Some SLRs of randomized trials have reported a possible increase in the incidence of severe infections with the use of certolizumab in the (indirect) comparison with other bDMARDs (moderate evidence), but this result has not been observed in registry studies [65-67, 69]. Lower intestinal perforation was more common in patients treated with tocilizumab (moderate evidence) [70]. Tuberculosis (TB) was more common in TNFi users than non-TNFi users. Among TNFi users, TB was more common in patients treated with adalimumab and infliximab compared with those treated with etanercept (moderate evidence) [68]. There were no differences among the bDMARD in the incidence of herpes zoster or neoplasia except for a possible increase in the rate of melanoma with the use of TNFi (very low evidence) $[64,71]$.

\section{Recommendation 7: The combination of bDMARD and} MTX is preferred over the use of bDMARD alone. (level of agreement: 9.87 )

bDMARDs are more effective when combined with csDMARDs, particularly MTX [19, 72-75].

Adalimumab + MTX improved ACR20, ACR50, ACR70, and ACR90 responses and functional capacity and pain (high evidence) and did not significantly increase the rate of treatment dropout due to adverse effects compared with adalimumab monotherapy (moderate evidence) [72].

Etanercept + MTX provided a better ACR50 response and lower radiographic progression compared with etanercept monotherapy (high evidence) and did not significantly affect the ACR70 response and dropout due to adverse events (moderate evidence) [73].

Golimumab + MTX improved the ACR50 response rate and did not significantly affect the ACR70 response, dropout due to adverse events, severe adverse events, and functional capacity compared with golimumab monotherapy (moderate evidence) [76].

Abatacept + MTX increased the remission rates (DAS28 <2.6) compared with abatacept monotherapy [19].

Higher ACR50 and ACR70 response rates were observed with rituximab + MTX compared with rituximab alone (the groups were compared with MTX monotherapy) [75].

In a randomized trial, tocilizumab monotherapy was not significantly different from tocilizumab + MTX for ACR50 and ACR70 responses, dropout due to adverse events, severe adverse events, and functional capacity after 24 weeks of treatment. However, other randomized trial found higher remission rates (DAS28<2.6) and lower radiographic progression with tocilizumab + MTX compared with tocilizumab monotherapy [77-79].

The use of csDMARD in combination with bDMARD appears to reduce the formation of antibodies against the biological agent, secondary failure. Studies that used bDMARDs combined with csDMARDs, such as leflunomide, confirmed the efficacy of this combination strategy, particularly in patients who presented adverse events or contraindications to MTX $[80,81]$.

Recommendation 8: In case of failure of an initial treatment scheme with bDMARD, a scheme with another bDMARD can be used. In cases of failure with TNFi, a second bDMARD of the same class or with another mechanism of action is effective and safe. (level of agreement: 9.37)

The use of another bDMARD is safe and effective after therapeutic failure of an initial treatment with bDMARD $[24,82]$. When the first bDMARD was an TNFi agent, the use of another TNFi agent was safe and effective in cases of treatment failure [83, 84].

Abatacept (high evidence), rituximab (high evidence), golimumab (moderate evidence), and tocilizumab (moderate evidence) were better than placebo for decreasing the number of painful and swollen joints after failure of TNFi treatment [82, 85-87].

Indirect comparisons did not allow the determination of superiority among abatacept, golimumab, rituximab, or tocilizumab in ACR50 and ACR70 responses when used after failure of the first bDMARD [88]. The risk of adverse events, including severe ones, and severe 
infections caused by these four biologicals after failure of the first bDMARD, was similar to placebo.

Although the use of a second TNFi agent after failure of the first is safe and effective, some studies suggest superior results for the ACR20 response, EULAR response criterion, and disease activity reduction when switching to a bDMARD with a different mechanism of action [82, 87, 89, 90]. These data must be confirmed in further studies. In other countries, rituximab has been shown to be the most cost-effective alternative among bDMARDs for the treatment of patients with previous failure to TNFi (very low evidence) [82, 85-87, 89, 91].

However, these results cannot be directly applied to the Brazilian context.

Recommendation 9: Tofacitinib can be used to treat RA after failure of bDMARD. (level of agreement: 9.81) Tofacitinib + MTX is effective after failure of TNFi, promoting a rapid and favorable ACR20 response and improving functional capacity and disease remission [92-97].

There are no available radiographic progression data for the use of tofacitinib after failure of bDMARD.

Recommendation 10: Corticosteroids, preferably at low doses for the shortest possible time, should be considered during periods of disease activity, and the risk-benefit ratio should also be considered. (level of agreement: 9.81 )

Corticosteroids are effective in treating RA when combined with csDMARD. Most of the analyzed studies used oral prednisone. The use of corticosteroids in RA reduced pain [98] (moderate evidence) and radiographic progression (high to low evidence) [99-102]. Prednisone + MTX compared with MTX alone reduced the need to switch treatment to bDMARD and did not increase the rate of adverse events [103]. However, low doses $(\leq 10 \mathrm{mg} /$ day of prednisone or equivalent) for the shortest possible time are recommended for managing periods of increased disease activity and minimizing adverse events. Special caution is necessary in patients with comorbidities that are potentially aggravated by corticosteroids.

\section{Recommendation 11: Reducing or spacing out bDMARD} doses is possible in patients in sustained remission. (level of agreement: 9.31)

Patients using bDMARD combined with csDMARD and in sustained remission (for at least 6 months) according to any composite disease activity index may receive lower bDMARD doses or the dose interval may be increased (moderate to low evidence) [104-112].

Patients with recent-onset RA (less than 6 months of symptoms) and low disease activity, suggestive of residual inflammation, rather than undergoing bDMARD dose reduction or dose interval increase, should be treated with another bDMARD or tsDMARD [113].

However, in patients with established RA and low disease activity or remission, bDMARD dose reduction or a dose interval increase should be evaluated on an individual basis [107-112, 114-116].

Lowering the bDMARD dose reduces costs (high evidence) $[114,117]$.

\section{Therapeutic strategies for treating RA in Brazil}

Treatment with DMARDs should be initiated as soon as the diagnosis of RA is established. Treatment should be adjusted as necessary by frequent clinical reassessments at 30-90-day intervals. Therapeutic strategies based on specific goals produce better outcomes for disease activity and functional capacity, with less radiographic structural damage compared with conventional treatments $[4,6,113]$. The goal is sustained remission $[118,119]$ or at least low disease activity, as assessed by a composite measure of disease activity, also taking into consideration the absolute decrease in the composite measure score (Tables 4, 5, and 6) [7, 113].

\section{First-line treatment: csDMARD}

First scheme

MTX is the first-choice csDMARD [6, 40, 120]. MTX may be initially prescribed as monotherapy or in combination with other csDMARD (example: MTX + leflunomide) [17]. Subcutaneous MTX is an alternative to cases of drug intolerance or poor response to oral MTX before changing or adding other csDMARD. Subcutaneous MTX is better tolerated and has greater bioavailability, potentially improving clinical efficacy compared with oral administration at the same dose [39].

In cases in which MTX is contraindicated, sulfasalazine [28] or leflunomide [25] may be used as the first option. Hydroxychloroquine (or when unavailable, chloroquine) may be used in monotherapy in cases of undifferentiated arthritis or disease with low potential for the development of radiographic erosions [6].

\section{Second scheme}

In cases in which there is no clinical response in 3 months or the therapeutic goal (sustained remission or low disease activity according to a composite measure of disease activity) is not achieved within 6 months with an optimum dose of MTX or in the presence of adverse effects, it is recommended to switch MTX for another csDMARD in monotherapy, such as leflunomide [25] or sulfasalazine [28], or a combination of MTX and other csDMARDs [41, 46]. The suggested combinations are MTX + hydroxychloroquine + sulfasalazine [41] or MTX + leflunomide [121]. Therapeutic progression should be rapid, with monthly assessments in the first 6 months of treatment and adjustment of doses and schedules as needed. 
Table 4 Composite measures of disease activity used in rheumatoid arthritis: components, calculation formula, and range of results

\begin{tabular}{|c|c|c|c|}
\hline Components & SDAl & CDAl & DAS28 (with 4 variables) \\
\hline Number of swollen joints & $\begin{array}{l}(0-28) \\
\text { Simple sum }\end{array}$ & $\begin{array}{l}(0-28) \\
\text { Simple sum }\end{array}$ & Square root of the simple sum \\
\hline Number of painful joints & $\begin{array}{l}(0-28) \\
\text { Simple sum }\end{array}$ & $\begin{array}{l}(0-28) \\
\text { Simple sum }\end{array}$ & Square root of the simple sum \\
\hline Acute phase reagents & $\begin{array}{l}\text { CRP } \\
(0.1-10 \mathrm{mg} / \mathrm{dL})\end{array}$ & - & $\begin{array}{l}\text { ESR 2-100 mm } \\
\text { or CRP } 0.1-10 \mathrm{mg} / \mathrm{dL} \text { logarithmic transformation }\end{array}$ \\
\hline $\begin{array}{l}\text { Global health assessment } \\
\text { (Patient) }\end{array}$ & & - & $0-100 \mathrm{~mm}$ \\
\hline $\begin{array}{l}\text { Assessment of disease activity } \\
\text { (Patient) }\end{array}$ & $(0-10 \mathrm{~cm})$ & $(0-10 \mathrm{~cm})$ & - \\
\hline $\begin{array}{l}\text { Assessment of disease activity } \\
\text { (Examiner) }\end{array}$ & $(0-10 \mathrm{~cm})$ & $(0-10 \mathrm{~cm})$ & - \\
\hline Total index & Simple sum & Simple sum & Calculation formula (requires a calculator) \\
\hline Index variation & $(0.1-86.0)$ & $(0-76)$ & $(0.49-9.07)$ \\
\hline
\end{tabular}

CDAl, clinical disease activity index; DAS28, disease activity index (28 joints); CRP, C-reactive protein; SDAl, simplified disease activity index; ESR, erythrocyte sedimentation rate. Assuming a variation of 2 to $100 \mathrm{~mm} / \mathrm{h}$ for ESR and of 0.1 to $10 \mathrm{mg} / \mathrm{dL}$ for CRP [6, 142].

\section{Corticosteroids, analgesics, and non-steroidal anti- inflammatory drugs}

Low doses of corticosteroids (maximum of $10 \mathrm{mg} /$ day of prednisone or equivalent) may be used at the beginning of treatment or when disease worsens. However, treatment for the shortest possible time is recommended to reduce the occurrence of adverse events. Intra-articular corticosteroids may be used when necessary for symptom control, particularly for monoarticular or oligoarticular arthritis [6]. Common analgesics (paracetamol and dipyrone) and weak opioids (tramadol and codeine) may be used on demand for the control of pain symptoms [6].

Non-steroidal anti-inflammatory drugs (NSAIDs) reduce pain (low to moderate evidence) and disease activity

Table 5 Definition of the status of activity of rheumatoid arthritis and respective cutoff points using composite disease activity indices

\begin{tabular}{lll}
\hline Index & Disease activity status & Cutoff points \\
\hline SDAl & Remission & $\leq 5$ \\
& Low & $>5$ and $\leq 20$ \\
& Moderate & $>20$ and $\leq 40$ \\
& High & $>40$ \\
CDAl & Remission & $\leq 2.8$ \\
& Low & $\leq 10$ \\
& Moderate & $>10$ and $\leq 22$ \\
DAS28 & High & $>22$ \\
& Remission & $\leq 2.6$ \\
& Low & $>2.6$ and $\leq 3.2$ \\
& Moderate & $>3.2$ and $\leq 5.1$ \\
& High & $>5.1$ \\
\hline
\end{tabular}

CDAl, clinical disease activity index; DAS28, disease activity index (28 joints); SDAl, simplified disease activity index [142]. (low evidence) and improve functional capacity (low evidence) in RA [122-127]. NSAIDs may be useful primarily at disease onset (because DMARDs do not have immediate action) and in cases of RA exacerbation [128, 129].

The choice of NSAID should be individualized because there is no demonstrated superior efficacy of one NSAID over another. Use for the shortest possible time is recommended. Additional caution is necessary in cases of risk factors for adverse events caused by NSAIDs, including advanced age, systemic arterial hypertension, heart failure, renal or hepatic dysfunction, gastrointestinal disease, arterial insufficiency, and coagulation disorders [130].

\section{Second-line treatment: bDMARD or tsDMARD}

The use of bDMARD or tsDMARD is recommended in cases in which there is no clinical response after 3 months using the second scheme of the first-line treatment, the therapeutic goal is not achieved in 6 months (remission or low disease activity according to a composite measure of disease activity), or in cases of drug toxicity or intolerance.

The bDMARD drugs used in the second-line treatment are TNFi (adalimumab, certolizumab, etanercept, golimumab, or infliximab), T-lymphocyte costimulation modulator (abatacept), and IL-6 receptor blocker (tocilizumab), combined with csDMARD (preferably MTX) [24, 41, 58, 94, 95].

Tocilizumab demonstrated similar efficacy in monotherapy compared to tocilizumab + MTX for most of the relevant clinical outcomes $[58,77,131]$.

Adalimumab, etanercept, certolizumab, golimumab, and abatacept can be used in monotherapy [16], but their efficacy may be lower compared with the combinations with csDMARDs [17]. 
Table 6 Classification of the therapeutic response in rheumatoid arthritis according to the variation in scores of the composite disease activity indices

\begin{tabular}{ll}
\hline Index & Response classification \\
\hline EULAR-DAS28 response & Good: drop $\geq 1.2$ points, reaching DAS28 $\leq 3.2$ \\
& Moderate: drop $>1.2$ points, maintenance of DAS28 $>3.2$; or drop $>0.6$ and $\leq 1.2$ points, reaching DAS28 $\leq 5.1$ \\
& Unresponsive: drop $>0.6$ and $\leq 1.2$ points, maintenance of DAS28 $>5.1$; or drop $\leq 0.6$ points \\
SDAl and CDAl response & Good: drop $\geq 85 \%$ in the score value \\
& Moderate: decrease $\geq 70$ and $<85 \%$ in the score value \\
& Weak: drop $\geq 50 \%$ and $<70 \%$ in the score value \\
& Unresponsive: drop $<50 \%$ in the score value \\
\hline
\end{tabular}

CDAl, clinical disease activity index; DAS28, disease activity index (28 joints); SDAl, simplified disease activity index [142-144].

Different bDMARDs have similar levels of clinical efficacy and safety [24, 42, 120]. Therefore, bDMARDs should be chosen on an individual basis, taking into account the costs and the presence of comorbidities that may be positively or negatively affected by the treatment choice. There is not necessarily a preference for one mechanism of action relative to another for treating RA.

The tsDMARD tofacitinib may be prescribed as the second line of treatment, preferably in combination with MTX [41] or in monotherapy in cases of contraindication to MTX. However, because of the higher availability of long-term safety and real-life data for bDMARDs, at present these regimens are preferred as the second-line treatment, and tsDMARDs are considered an alternative to bDMARDs [9]. Although evidence supports the use of the bDMARD rituximab after failure of csDMARD, anti-CD20 is formally approved for treating RA only after TNFi failure and has been used as the third-line treatment in this therapeutic strategy. Nonetheless, rituximab may be considered as the first choice among bDMARDs for patients with rheumatoid factor (RF) or antibodies against citrullinated cyclic peptide (anti-CCP), with contraindications to other bDMARDs, or an associated diagnosis of lymphoma [132]. Patients with poor prognosis factors [5], including high disease activity, high number of painful or swollen joints, high RF and/or anti-CCP titers, and early occurrence of radiographic erosions, may benefit from a more aggressive treatment, including indication of a bDMARD after failure of the first csDMARD scheme, although more evidence is required to support this indication.

There is no evidence of cost-effectiveness supporting the use of bDMARD as the first-line treatment for RA in Brazil. The concomitant use of two bDMARDs or one bDMARD combined with a tsDMARD is not recommended [42].

\section{Third-line treatment: After failure of the first bDMARD or tsDMARD}

The third-line treatment is used in cases the therapeutic goal (sustained remission or low disease activity according to a composite measure of disease activity) is not achieved in 6 months using the second-line treatment (indicating primary failure to bDMARD or tsDMARD), or loss of the previous response (secondary failure to bDMARD or tsDMARD), or cases of drug toxicity or intolerance.

The drugs available for the third-line treatment are the bDMARDs TNFi (adalimumab, certolizumab, etanercept, golimumab, or infliximab), T-lymphocyte costimulation modulator (abatacept), IL-6 receptor blocker (tocilizumab), anti-CD20 (rituximab), and the tsDMARD tofacitinib, combined with csDMARD (preferably MTX) [96]. Rituximab, when considered, should be indicated to patients with positive RF or anti-CCP $[96,132]$.

When a bDMARD is used as the second-line treatment, switching to another bDMARD or to a tsDMARD is recommended as the third-line treatment. A second TNFi drug (particularly in cases of secondary failure), switching to a bDMARD with a different mechanism of action (abatacept, tocilizumab, or rituximab) [82] or switching to a tsDMARD (tofacitinib) is recommended in cases in which the first bDMARD is a TNFi $[82,97]$. Patients with failure to a first TNFi show improvements with a second TNFi $[24,59,84,91]$. However, there are uncertainties about the cost-effectiveness of this strategy because it can result in lower response rates compared with switching the mechanism of action [87, 90, 91]. If the first bDMARD is not a TNFi, the options include prescribing another bDMARD with a mechanism of action distinct from that of the first bDMARD (including TNFi) or the use of tsDMARD.

When a tsDMARD is used as the second-line treatment, the option for the third-line treatment is switching to bDMARDs. However, this strategy requires careful clinical observation because there is no available evidence to date on the efficacy and safety of the sequential use of bDMARDs after failure of tsDMARD (tofacitinib). Until specific information is available, caution is advised on the sequential use of drugs that interfere with IL-6 (tocilizumab) and the JAK-STAT signaling pathway (tofacitinib) in patients with toxicity to any of these medications because the effects of IL- 6 are mediated by the JAK-STAT pathway [40].

The treatment sequence depends on the specificities of each case and the discretion of the physician. In the 
case of failure or toxicity to a drug used in the third line of treatment, the next step is to switch to another (bDMARD or tsDMARD) with the same level of complexity and that has not been used previously. A minimum of 3 months and maximum of 6 months of clinical evaluation are recommended before switching a therapeutic regimen due to poor clinical response.

\section{Gradual reduction of medication dose and treatment discontinuation}

There are no data to support setting any limit for the RA treatment duration. However, patients using bDMARD in sustained remission may receive a bDMARD dose reduction or dose interval increase. Although disease reactivation may occur in some cases, disease control is usually reestablished with the return to the previous dose schedule (moderate to low evidence) $[19,23,104,105,114,133]$. In cases of complete and sustained remission (at least 6 months), gradual and careful treatment withdrawal may be attempted in the following sequence: first NSAIDs, followed by corticosteroids, and bDMARD or tsDMARD, but maintaining the use of csDMARD. After the withdrawal of bDMARD, if sustained clinical remission is maintained, reduction of the csDMARD dose can be carefully attempted. Exceptionally, withdrawal of csDMARD might be feasible in cases in which clinical remission continues to be sustained $[40,116]$.

Sustained drug-free remission is rare, and the probability of disease exacerbation (flares) is higher in patients with long-standing disease, the presence of synovitis on ultrasound (gray scale or power Doppler), and a positive anti-CCP [116].

\section{Biosimilar drugs}

Biosimilar bDMARDs (bsDMARDs) are very similar to their original bDMARDs (boDMARDs) regarding quality, molecular structure, biological activity, clinical efficacy, safety, and immunogenicity in comparability tests, and these drugs fulfill strict regulatory criteria [134].

bsDMARDs have been shown to be safe and effective when used as an alternative to boDMARDs (moderate evidence). There were no differences in ACR20 and ACR70 response rates, disease activity (moderate evidence), or severe adverse events of the bsDMARDs adalimumab, etanercept, infliximab, and rituximab compared with their respective boDMARDs [134-140]. The development of anti-drug antibodies was similar between bsDMARDs and boDMARDs (moderate evidence), and lower for the bsDMARD of etanercept compared with the boDMARD (high evidence) [134].

However, the demonstration of biosimilarity should not be understood as evidence of interchangeability. Interchangeability, when referring to bsDMARDs, is defined by the simultaneous presence of two requirements [1]: the expected clinical outcome using the bsDMARD is similar to that produced by the corresponding boDMARD in any patient [2]; repeated switching between the boDMARD and the bsDMARD presents no additional safety or efficacy risk compared with the continued use of the reference product [141].

The SBR advocates the need for an objective demonstration of interchangeability between any boDMARD and its correspondent bsDMARD using studies specifically designed for this purpose. Until such studies are available and interchangeability conditions are regulated in Brazil, boDMARDs should not be automatically replaced with bsDMARDs without the consent of the prescriber and patient.

\section{Pharmacological treatment flowchart for RA in Brazil}

The therapeutic strategies proposed by the RA Committee of the SBR for RA treatment in Brazil are summarized in Fig. 1.

\section{Treatment monitoring}

For patients with active disease, especially in the initial phase of the disease (first 6 months of manifestations), intensive follow-up with monthly visits and, when necessary, rapid treatment escalation are recommended [6].

The efficacy and safety of the therapeutic intervention should be evaluated at each visit considering the comorbidities of the patient and aiming to achieve the lowest possible disease activity (if remission is not possible), as well as improve function and quality of life. Visits can be spaced out for patients with established disease, particularly those with controlled disease [6].

The clinical history of patients who are eligible for treatment with bDMARD should be analyzed for the presence of severe active infection, TB, or untreated latent $\mathrm{TB}$, moderate to severe heart failure, multiple sclerosis or optic neuritis, previous hypersensitivity to TNFi, malignancy or lymphoma, and congenital or acquired immunodeficiency. Complementary examinations to identify hepatitis B virus, hepatitis $\mathrm{C}$ virus, and HIV, as well as chest X-ray and the tuberculin test, should be part of the pretreatment evaluation [6].

\section{Conclusions}

Advances in RA diagnosis and treatment have allowed improvements in disease outcome. The presence of a rheumatologist is critical in evaluating and treating patients with RA because these professionals are trained to make an early diagnosis and are familiar with the available drug therapies, indications, management, and adverse events.

The Brazilian scenario has specificities that require attention, including the local availability of medications 
and the socioeconomic status of the population. Brazil is a large country with a growing population, requiring rational allocation of resources to allow broad and equitable access of the population to medications and other health technologies.

The recommendations presented herein seek to provide scientific evidence to Brazilian rheumatologists, considering the therapeutic efficacy, safety, and costs, together with the critical assessment and experience of a panel of experts to standardize the management of RA in the national socioeconomic context, but maintaining the autonomy of the physician in choosing different therapeutic options. These recommendations should be updated periodically because of the rapid development of this field of knowledge. The 2017 SBR recommendations and supporting documents could be accessed online

\section{Additional file}

Additional file 1: Methodological details, expanded results and rationale of the answers to the formulated questions of the SLR that supported the present recommendations. (DOCX $980 \mathrm{~kb}$ )

\section{Acknowledgements}

The authors wish to acknowledge the researchers Tais Freire Galvão and Marcus Tolentino Silva, who performed the systematic review that is presented in detail in the Additional file 1, funded by the Brazilian Society of Rheumatology.

\section{Funding}

Brazilian Society of Rheumatology. The funding body had no role in the design of the study and collection, analysis, and interpretation of data and in writing the manuscript.

\section{Authors' contributions}

All authors made substantial contributions to the acquisition of data, have been involved in drafting the manuscript or revising it critically for important intellectual content, gave final approval of the version to be published and have participated sufficiently in the work to take public responsibility for appropriate portions of the content; and agreed to be accountable for all aspects of the work in ensuring that questions related to the accuracy or integrity of any part of the work are appropriately investigated and resolved.

\section{Ethics approval and consent to participate}

Not applicable.

\section{Competing interests}

Licia Maria Henrique da Mota Has received personal or institutional support from Abbvie, Janssen, Pfizer and Roche; has delivered speeches at events related to this work and sponsored by Abbvie, Janssen, Pfizer, Roche and UCB. Financial competing interest: none.

Adriana Maria Kakehasi Research funds: CNPq, SBR, FAPEMIG Support for Scientific Events: Abbvie, BMS, Janssen Lecture Fees: UCB, Janssen, Pfizer, Roche, BMS Clinical research: Roche, Pfizer Advisory board: Janssen, Roche, BMS, Pfizer.

Ana Paula Monteiro Gomides Assistance for participation in events: Pfizer. Angela Luzia Branco Pinto Duarte Lecture Fees: Janssen, BMS.

Bóris Afonso Cruz Support for Scientific Events and Lecture Fees: Abbvie, BMS, Janssen, Novartis, Pfizer, Roche.

Claiton Viegas Brenol Has participated in clinical and/or experimental studies related to this work and sponsored by the PI (Abbvie, BMS, Janssen, Pfizer and Roche); has received personal or institutional support from the PI (Abbvie, BMS, Janssen, Pfizer and Roche); has delivered speeches at events related to this work and sponsored by the PI (Abbvie, Janssen, Pfizer and
Roche). Financial competing interest: none. Non-financial competing interest: none.

Cleandro Pires de Albuquerque Personal fees and/or non-financial support from Pfizer, Abbvie, AstraZeneca, Janssen, Bristol-Myers-Squibb, Roche,

Novartis and UCB, outside the submitted work.

Geraldo da Rocha Castelar Pinheiro Consultants for: Abbvie, Bristol-Myers

Squibb, Eli Lilly, Glaxo Smith Kline, Janssen, Pfizer, Sanofi Genzyme and Roche.

leda Maria Magalhães Laurindo Consultants for Abbvie, Bristol, GSK, Janssen, Lilly, Pfizer and UCB; has received personal or institutional support from Abbvie, Bristol, Janssen, Lilly, Pfizer, UCB; has delivered speeches at events related to this work and sponsored by Abbvie, Bristol, Janssen, Lilly, Pfizer, Roche and UCB.

Ivanio Alves Pereira Has received consulting fees,speaking fees and supporting for internationals congresses from Roche,Pfizer, Janssen, Novartis, Bristol-Myers-Squibb, UCB Pharma, Eli-Lilly, AbbVie, and EMS.

Manoel Barros Bertolo Has participated in clinical and/or experimental studies related to this work and sponsored by the PI (Roche); has delivered speeches at events related to this work and sponsored by the PI (Abbvie, Pfizer). Financial competing interest: none. Non-financial competing interest: none.

Mariana Peixoto Guimarães Ubirajara Silva de Souza Support in Congresses: UCB, Roche, Janssen Lectures with fee: UCB, Janssen, Abbvie, Pfizer, Roche, BMS Clinical research: GSK, UCB, Abbvie Advisory Board: Janssen. Max Vitor Carioca Freitas Speaker at events related to this work and sponsored by Abbvie, Novartis, Roche, Pfizer and UCB. Managing Partner of Integrare Therapeutics.

Paulo Louzada Júnior Sponsored by: Bristol-Myers Squibb, UCB, Pfizer Board Participation: Pfizer.

Ricardo Machado Xavier Lectures, consultancies: Abbvie, BMS, GSK, Janssen, Lilly, Novartis, Pfizer, Roche, UCB Clinical trials: Abbvie, UCB, Pfizer, GSK, Lilly. Rina Dalva Neubarth Giorgi Has received consulting fees,speaking fees and supporting for internationals congresses from Roche,Pfizer,Bristol-MyersSquibb, UCB Pharma, Eli-Lilly,AbbVie,Abbott and EMS.

\section{Publisher's Note}

Springer Nature remains neutral with regard to jurisdictional claims in published maps and institutional affiliations.

\section{Author details}

${ }^{1}$ Programa de Pós-graduação em Ciências Médicas, Faculdade de MedicinaUniversidade de Brasília; Serviço de Reumatologia, Hospital Universitário de Brasília, Universidade de Brasília, Brasília, Brazil. ²Disciplina de Reumatologia, Faculdade de Medicina, Universidade Federal de Minas Gerais, Belo Horizonte, Brazil. ${ }^{3}$ Centro Universitário de Brasília- UniCEUB, Brasília, Brazil. ${ }^{4}$ Universidade Federal de Pernambuco, Recife, Brazil. ${ }^{5}$ Hospital Vera Cruz, Belo Horizonte, Brazil. '5erviço de Reumatologia, Departamento de Medicina Interna, Serviço de Reumatologia, Hospital de Clínicas de Porto Alegre, Universidade Federal do Rio Grande do Sul, Porto Alegre, Brazil. ${ }^{7}$ Serviço de Reumatologia, Hospital Universitário de Brasília, Universidade de Brasília, Brasília, Brazil. ${ }^{8}$ Disciplina de Reumatologia, Departamento de Medicina Interna, Universidade do Estado do Rio de Janeiro, Rio de Janeiro, Brazil. ${ }^{9}$ Universidade Nove de Julho, São Paulo, Brazil. ${ }^{10}$ Universidade do Sul de Santa Catarina, Florianópolis, Brazil. ${ }^{11}$ Disciplina de Reumatologia, Faculdade de Ciências Médicas, Universidade Estadual de Campinas, Campinas, Brazil.

${ }^{12}$ Santa Casa de Belo Horizonte, Belo Horizonte, Brazil. ${ }^{13}$ Universidade de Fortaleza, Fortaleza, Brazil. ${ }^{14}$ Disciplina de Reumatologia, Faculdade de Medicina de Universidade de Ribeirão Preto, Universidade de São Paulo, Ribeirão Preto, Brazil. ${ }^{15}$ Serviço de Reumatologia, Hospital do Servidor Público Estadual de São Paulo, Instituto de Assistência Médica ao Servidor Público Estadual, São Paulo, Brazil. ${ }^{16}$ Rheos, Centro Médico Lúcio Costa, SGAS 610, bloco 1, salas T50- T51, L2 Sul, Asa Sul, Brasília, DF 70200700, Brazil.

Received: 5 March 2018 Accepted: 18 April 2018

Published online: 24 May 2018

\section{References}

1. Silman A HM. Epidemiology of rheumatic diseases. Oxford University Press; 2000 . 
2. Minichiello E, Semerano L, Boissier M-C. Time trends in the incidence, prevalence, and severity of rheumatoid arthritis: a systematic literature review. Joint Bone Spine. 2016;83(6):625-30.

3. Senna ER, De Barros ALP, Silva EO, Costa IF, Pereira LVB, Ciconelli RM, et al. Prevalence of rheumatic diseases in Brazil: a study using the COPCORD approach. J Rheumatol. 2004;31(3):594-7.

4. Burmester GR, Bijlsma JWJ, Cutolo M, Mclnnes IB. Managing rheumatic and musculoskeletal diseases - past, present and future. Nat Rev Rheumatol. 2017;13(7):443-8.

5. Mota LMH, Cruz BA, Brenol CV, Pereira IA, Fronza LSR, Bertolo MB, et al. Consenso da Sociedade Brasileira de Reumatologia 2011 para o diagnóstico e avaliação inicial da artrite reumatoide. Rev Bras Reumatol. 2011;51(3):207-19.

6. Mota LMH, Cruz BA, Brenol CV, Pereira IA, Rezende-fronza LS, Bertolo MB, et al. Consenso 2012 da Sociedade Brasileira de Reumatologia para o tratamento da artrite reumatoide. Rev Bras Reumatol [Internet]. 2012;52(2):152-74

7. Pereira IA, Mota LMH, Cruz BA, Brenol CV, LSR F, Bertolo MB, et al. Consenso 2012 da Sociedade Brasileira de Reumatologia sobre o manejo de comorbidades em pacientes com artrite reumatoide. Rev Bras Reumatol Bras Reumatol. 2012;52(4):474-95.

8. Brenol CV, da Mota LMH, Cruz BA, Pileggi GS, Pereira IA, Rezende LS, et al. 2012 Brazilian society of rheumatology consensus on vaccination of patients with rheumatoid arthritis. Rev Bras Reumatol [Internet]. 2013;53(1): 13-23. Elsevier.

9. Mota LMH, Cruz BA, de ACP, Gonçalves DP, IMM L, Pereira IA, et al. Posicionamento sobre o uso de tofacitinibe no algoritmo do Consenso 2012 da Sociedade Brasileira de Reumatologia para o tratamento da artrite reumatoide. Rev Bras Reumatol [Internet]. 2015;55(6):512-21.

10. Cochrane Handbook for Systematic Reviews of Interventions. The Cochrane Collaboration.; 2011

11. Shea BJ, Grimshaw JM, Wells GA, Boers M, Andersson N, Hamel C, et al. Development of AMSTAR: a measurement tool to assess the methodological quality of systematic reviews. BMC Med Res Methodol. 2007;7:10.

12. Schünemann H, Brożek J, Guyatt G, Oxman A. Handbook for grading the quality of evidence and the strength of recommendations using the GRADE approach. 2013.

13. Einarsson JT, Geborek P, Saxne T, Kristensen LE, Kapetanovic MC. Sustained remission improves physical function in patients with established rheumatoid arthritis, and should be a treatment goal: a prospective observational cohort study from southern Sweden. J Rheumatol. 2016;43(6):1017-23.

14. Radner H, Alasti F, Smolen JS, Aletaha D. Physical function continues to improve when clinical remission is sustained in rheumatoid arthritis patients. Arthritis Res Ther. 2015;17(1):203.

15. Ruyssen-Witrand A, Guernec G, Nigon D, Tobon G, Jamard B, Rat A-C, et al. Aiming for SDAl remission versus low disease activity at 1 year after inclusion in ESPOIR cohort is associated with better 3-year structural outcomes. Ann Rheum Dis. 2015;74(9):1676-83.

16. Tarp S, Furst DE, Dossing A, Ostergaard M, Lorenzen T, Hansen MS, et al. Defining the optimal biological monotherapy in rheumatoid arthritis: a systematic review and meta-analysis of randomised trials. Semin Arthritis Rheum. 2017;46(6):699-708.

17. Stevenson M, Archer R, Tosh J, Simpson E, Everson-Hock E, Stevens J, et al. Adalimumab, etanercept, infliximab, certolizumab pegol, golimumab, tocilizumab and abatacept for the treatment of rheumatoid arthritis not previously treated with disease-modifying antirheumatic drugs and after the failure of conventional disease-modifying antirheumatic drugs only: systematic review and economic evaluation. Health Technol Assess. 2016;20(35):1-610.

18. Nam JL, Ramiro S, Gaujoux-Viala C, Takase K, Leon-Garcia M, Emery P, et al. Efficacy of biological disease-modifying antirheumatic drugs: a systematic literature review informing the 2013 update of the EULAR recommendations for the management of rheumatoid arthritis. Ann Rheum Dis. 2014;73(3):516-28

19. Emery P, Burmester GR, Bykerk VP, Combe BG, Furst DE, Barre E, et al. Evaluating drug-free remission with abatacept in early rheumatoid arthritis: results from the phase $3 \mathrm{~b}$, multicentre, randomised, active-controlled AVERT study of 24 months, with a 12-month, double-blind treatment period. Ann Rheum Dis. 2015:74(1):19-26.

20. Lethaby A, Lopez-Olivo MA, Maxwell L, Burls A, Tugwell P, Wells GA. Etanercept for the treatment of rheumatoid arthritis. Cochrane Database Syst Rev. 2013;5:CD004525.
21. Emery P, Fleischmann RM, Strusberg I, Durez P, Nash P, Amante EJB, et al. Efficacy and safety of subcutaneous Golimumab in methotrexate-naive patients with rheumatoid arthritis: five-year results of a randomized clinical trial. Arthritis Care Res (Hoboken). 2016;68(6):744-52.

22. Lopez-Olivo MA, Amezaga Urruela M, McGahan L, Pollono EN, SuarezAlmazor ME. Rituximab for rheumatoid arthritis. Cochrane Database Syst Rev. 2015;1:CD007356.

23. Ruiz Garcia V, Jobanputra P, Burls A, Cabello JB, Vela Casasempere P, BortMarti S, et al. Certolizumab pegol (CDP870) for rheumatoid arthritis in adults. Cochrane database Syst Rev. 2014;9:CD007649.

24. Nam JL, Takase-Minegishi K, Ramiro S, Chatzidionysiou K, Smolen JS, van der Heijde D, et al. Efficacy of biological disease-modifying antirheumatic drugs: a systematic literature review informing the 2016 update of the EULAR recommendations for the management of rheumatoid arthritis. Ann Rheum Dis. 2017;76(6):1102-7.

25. Osiri M, Shea B, Robinson V, Suarez-Almazor M, Strand V, Tugwell $P$, et al. Leflunomide for treating rheumatoid arthritis. Cochrane database Syst Rev. 2003;1:CD002047.

26. Donahue KE, Gartlehner G, Jonas DE, Lux L, Thieda P, Jonas BL, et al. Systematic review: comparative effectiveness and harms of diseasemodifying medications for rheumatoid arthritis. Ann Intern Med. 2008; 148(2):124-34.

27. Lopez-Olivo MA, Siddhanamatha HR, Shea B, Tugwell P, Wells GA, SuarezAlmazor ME. Methotrexate for treating rheumatoid arthritis. Cochrane Database Syst Rev. 2014;6:CD000957.

28. Suarez-Almazor ME, Belseck E, Shea B, Wells G, Tugwell P. Sulfasalazine for rheumatoid arthritis. Cochrane Database Syst Rev. 2000;2:CD000958.

29. Zeb S, Wazir N, Waqas M, Taqweem A, Taqweem A. Comparison of shortterm efficacy of leflunomide and methotrexate in active rheumatoid arthritis. J Postgrad Med Inst. 2016;30(2):177-80.

30. Ishaq M, Muhammad JS, Hameed K, Mirza Al. Leflunomide or methotrexate? Comparison of clinical efficacy and safety in low socio-economic rheumatoid arthritis patients. Mod Rheumatol. 2011;21(4):375-80.

31. Emery P, Breedveld FC, Lemmel EM, Kaltwasser JP, Dawes PT, Gomor B, et al. A comparison of the efficacy and safety of leflunomide and methotrexate for the treatment of rheumatoid arthritis. Rheumatology (Oxford). 2000;39(6):655-65

32. Strand V, Cohen S, Schiff M, Weaver A, Fleischmann R, Cannon G, et al. Treatment of active rheumatoid arthritis with leflunomide compared with placebo and methotrexate. Leflunomide rheumatoid arthritis investigators group. Arch Intern Med. 1999;159(21):2542-50.

33. Jaimes-Hernandez J, Melendez-Mercado Cl, Mendoza-Fuentes A, ArandaPereira P, Castaneda-Hernandez G. Efficacy of leflunomide 100mg weekly compared to low dose methotrexate in patients with active rheumatoid arthritis. Double blind, randomized clinical trial. Reumatol Clin. 2012;8(5):243-9.

34. Smolen JS, Kalden JR, Scott DL, Rozman B, Kvien TK, Larsen A, et al. Efficacy and safety of leflunomide compared with placebo and sulphasalazine in active rheumatoid arthritis: a double-blind, randomised, multicentre trial. European Leflunomide Study Group Lancet (London, England). 1999; 353(9149):259-66

35. Haagsma CJ, van Riel PL, de Jong AJ, van de Putte LB. Combination of sulphasalazine and methotrexate versus the single components in early rheumatoid arthritis: a randomized, controlled, double-blind, 52 week clinical trial. Br J Rheumatol. 1997;36(10):1082-8.

36. Dougados $\mathrm{M}$, Combe B, Cantagrel A, Goupille P, Olive P, Schattenkirchner $M$, et al. Combination therapy in early rheumatoid arthritis: a randomised, controlled, double blind 52 week clinical trial of sulphasalazine and methotrexate compared with the single components. Ann Rheum Dis. 1999:58(4):220-5.

37. Conway R, Low C, Coughlan RJ, O'Donnell MJ, Carey JJ. Risk of liver injury among methotrexate users: a meta-analysis of randomised controlled trials. Semin Arthritis Rheum. 2015;45(2):156-62

38. Conway R, Low C, Coughlan RJ, O'Donnell MJ, Carey JJ. Methotrexate and lung disease in rheumatoid arthritis: a meta-analysis of randomized controlled trials. Arthritis Rheumatol (Hoboken, NJ). 2014;66(4):803-12.

39. Li D, Yang Z, Kang P, Xie X. Subcutaneous administration of methotrexate at high doses makes a better performance in the treatment of rheumatoid arthritis compared with oral administration of methotrexate: a systematic review and meta-analysis. Semin Arthritis Rheum. 2016;45(6):656-62.

40. Smolen JS, Landewe R, Bijlsma J, Burmester G, Chatzidionysiou K, Dougados $M$, et al. EULAR recommendations for the management of rheumatoid 
arthritis with synthetic and biological disease-modifying antirheumatic drugs: 2016 update. Ann Rheum Dis. 2017;76(6):960-77.

41. Hazlewood GS, Barnabe C, Tomlinson G, Marshall D, Devoe D, Bombardier C. Methotrexate monotherapy and methotrexate combination therapy with traditional and biologic disease modifying antirheumatic drugs for rheumatoid arthritis: abridged Cochrane systematic review and network meta-analysis. BMJ. 2016;353:11777.

42. Donahue K, Jonas D, Hansen R, Roubey R, Jonas B, Lux L, et al. Drug therapy for rheumatoid arthritis in adults: an update. Comp Eff Rev [Internet]. 2012;55:1-1073.

43. De Cock D, De Saedeleer A, Van der Elst K, Stouten V, Joly J, Westhovens R, et al. A Cost-Effectiveness Analysis of Different Intensive Combination Therapies for Early Rheumatoid Arthritis: 1 Year Results of The Carera Trial. Ann Rheum Dis [Internet]. 2016;75(Suppl 2):121. Available from: https://doi org/10.1136/annrheumdis-2016-eular.4139

44. Shashikumar NS, Shivamurthy MC, Chandrashekara S. Evaluation of efficacy of combination of methotrexate and hydroxychloroquine with leflunomide in active rheumatoid arthritis. Indian J Pharmacol. 2010;42(6):358-61.

45. Verschueren P, De Cock D, Corluy L, Joos R, Langenaken C, Taelman V, et al. Methotrexate in combination with other DMARDs is not superior to methotrexate alone for remission induction with moderate-to-high-dose glucocorticoid bridging in early rheumatoid arthritis after 16 weeks of treatment: the CareRA trial. Ann Rheum Dis. 2015;74(1):27-34.

46. Makinen $\mathrm{H}$, Kautiainen $\mathrm{H}$, Hannonen $\mathrm{P}$, Mottonen $\mathrm{T}$, Leirisalo-Repo $\mathrm{M}$, Laasonen $L$, et al. Sustained remission and reduced radiographic progression with combination disease modifying antirheumatic drugs in early rheumatoid arthritis. J Rheumatol. 2007;34(2):316-21.

47. den Uyl D, ter Wee M, Boers M, Kerstens P, Voskuyl A, Nurmohamed M, et al. A non-inferiority trial of an attenuated combination strategy ('COBRAlight') compared to the original COBRA strategy: clinical results after 26 weeks. Ann Rheum Dis. 2014;73(6):1071-8.

48. Verschueren P, De Cock D, Corluy L, Joos R, Langenaken C, Taelman V, et al. Effectiveness of methotrexate with step-down glucocorticoid remission induction (COBRA slim) versus other intensive treatment strategies for early rheumatoid arthritis in a treat-to-target approach: 1-year results of CareRA, a randomised pragmatic open-la. Ann Rheum Dis. 2017;76(3):511-20.

49. Karstila KL, Rantalaiho VM, Mustonen JT, Mottonen T, Hannonen PJ, Leirisalo-Repo $M$, et al. Renal safety of initial combination versus single DMARD therapy in patients with early rheumatoid arthritis: an 11-year experience from the FIN-RACo trial. Clin Exp Rheumatol. 2010;28(1):73-8

50. Gaujoux-Viala C, Smolen JS, Landewe R, Dougados M, Kvien TK, Mola EM, et al. Current evidence for the management of rheumatoid arthritis with synthetic disease-modifying antirheumatic drugs: a systematic literature review informing the EULAR recommendations for the management of rheumatoid arthritis. Ann Rheum Dis. 2010;69(6):1004-9.

51. Klarenbeek NB, Guler-Yuksel M, van der Kooij SM, Han KH, Ronday HK, Kerstens PJSM, et al. The impact of four dynamic, goal-steered treatment strategies on the 5-year outcomes of rheumatoid arthritis patients in the BeSt study. Ann Rheum Dis. 2011;70(6):1039-46.

52. Dougados M, Emery P, Lemmel EM, Zerbini CAF, Brin S, van Riel P. When a DMARD fails, should patients switch to sulfasalazine or add sulfasalazine to continuing leflunomide? Ann Rheum Dis. 2005:64(1):44-51.

53. Capell HA, Madhok R, Porter DR, Munro RAL, Mclnnes IB, Hunter JA, et al Combination therapy with sulfasalazine and methotrexate is more effective than either drug alone in patients with rheumatoid arthritis with a suboptimal response to sulfasalazine: results from the double-blind placebocontrolled MASCOT study. Ann Rheum Dis. 2007;66(2):235-41.

54. Nam JL, Winthrop KL, van Vollenhoven RF, Pavelka K, Valesini G, Hensor EMA, et al. Current evidence for the management of rheumatoid arthritis with biological disease-modifying antirheumatic drugs: a systematic literature review informing the EULAR recommendations for the management of RA. Ann Rheum Dis. 2010;69(6):976-86.

55. Chatzidionysiou K, Emamikia S, Nam J, Ramiro S, Smolen J, van der Heijde D, et al. Efficacy of glucocorticoids, conventional and targeted synthetic disease-modifying antirheumatic drugs: a systematic literature review informing the 2016 update of the EULAR recommendations for the management of rheumatoid arthritis. Ann Rheum Dis. 2017:76(6):1102-7.

56. Gaujoux-Viala C, Nam J, Ramiro S, Landewe R, Buch MH, Smolen JS, et al. Efficacy of conventional synthetic disease-modifying antirheumatic drugs, glucocorticoids and tofacitinib: a systematic literature review informing the
2013 update of the EULAR recommendations for management of rheumatoid arthritis. Ann Rheum Dis. 2014;73(3):510-5.

57. Guyot $P$, Taylor $P$, Christensen R, Pericleous L, Poncet C, Lebmeier M, et al. Abatacept with methotrexate versus other biologic agents in treatment of patients with active rheumatoid arthritis despite methotrexate: a network meta-analysis. Arthritis Res Ther. 2011;13(6):R204.

58. Jansen JP, Buckley F, Dejonckheere F, Ogale S. Comparative efficacy of biologics as monotherapy and in combination with methotrexate on patient reported outcomes (PROs) in rheumatoid arthritis patients with an inadequate response to conventional DMARDs-a systematic review and network meta-analysis. Health Qual Life Outcomes. 2014;12:102.

59. Schiff $M$, Weinblatt ME, Valente $R$, van der Heijde D, Citera G, Elegbe A, et al Head-to-head comparison of subcutaneous abatacept versus adalimumab for rheumatoid arthritis: two-year efficacy and safety findings from AMPLE trial. Ann Rheum Dis. 2014;73(1):86-94.

60. Porter D, van Melckebeke J, Dale J, Messow CM, McConnachie A, Walker A, et al. Tumour necrosis factor inhibition versus rituximab for patients with rheumatoid arthritis who require biological treatment (ORBIT): an openlabel, randomised controlled, non-inferiority, trial. Lancet (London, England). 2016;388(10041):239-47.

61. Schiff M, Keiserman M, Codding C, Songcharoen S, Berman A, Nayiager S, et al. Efficacy and safety of abatacept or infliximab vs placebo in ATTEST: a phase III, multi-Centre, randomised, double-blind, placebo-controlled study in patients with rheumatoid arthritis and an inadequate response to methotrexate. Ann Rheum Dis. 2008;67(8):1096-103.

62. Benucci M, Stam WB, Gilloteau I, Sennfalt K, Leclerc A, Maetzel A, et al. Abatacept or infliximab for patients with rheumatoid arthritis and inadequate response to methotrexate: an Italian trial-based and real-life cost-consequence analysis. Clin Exp Rheumatol. 2013;31(4):575-83.

63. Nobre MRC, Costa FM, Taino B, Kiyomoto HD, Rosa GF. Annual Expenditure on Anti-Tnf Treatment of Rheumatoid Arthritis for the Public Health System in Brazil. Value Heal [Internet]. 2013;16(7):A561. Elsevier.

64. Che H, Lukas C, Morel J, Combe B. Risk of herpes/herpes zoster during antitumor necrosis factor therapy in patients with rheumatoid arthritis. Systematic review and meta-analysis. Joint Bone Spine. 2014;81(3):215-21.

65. Singh JA, Wells GA, Christensen R, Tanjong Ghogomu E, Maxwell L, Macdonald JK, et al. Adverse effects of biologics: a network meta-analysis and Cochrane overview. Cochrane Database Syst Rev. 2011;2:CD008794.

66. de La Forest Divonne M, Gottenberg JE, Salliot C. Safety of biologic DMARDs in RA patients in real life: a systematic literature review and metaanalyses of biologic registers. Joint Bone Spine. 2017;84(2):133-40.

67. Tarp S, Eric Furst D, Boers M, Luta G, Bliddal H, Tarp U, et al. Risk of serious adverse effects of biological and targeted drugs in patients with rheumatoid arthritis: a systematic review meta-analysis. Rheumatology (Oxford). 2017:56(3):417-25

68. Ai J-W, Zhang S, Ruan Q-L, Yu Y-Q, Zhang B-Y, Liu Q-H, et al. The risk of tuberculosis in patients with rheumatoid arthritis treated with tumor necrosis factor-alpha antagonist: a Metaanalysis of both randomized controlled trials and registry/cohort studies. J Rheumatol. 2015;42(12):2229-37.

69. Ramiro S, Gaujoux-Viala C, Nam JL, Smolen JS, Buch M, Gossec L, et al. Safety of synthetic and biological DMARDs: a systematic literature review informing the 2013 update of the EULAR recommendations for management of rheumatoid arthritis. Ann Rheum Dis. 2014;73(3):529-35.

70. Strangfeld A, Richter A, Siegmund B, Herzer P, Rockwitz K, Demary W, et al. Risk for lower intestinal perforations in patients with rheumatoid arthritis treated with tocilizumab in comparison to treatment with other biologic or conventional synthetic DMARDs. Ann Rheum Dis. 2017;76(3):504-10.

71. Suissa S, Baker N, Kawabata H, Ray NST. Comparative risk of malignancy with initiation of Abatacept and other biologics in patients with rheumatoid arthritis: a cohort analysis of a United States claims database. Ann Rheum Dis. 2016;75:719-20.

72. Breedveld FC, Weisman MH, Kavanaugh AF, Cohen SB, Pavelka K, van Vollenhoven $\mathrm{R}$, et al. The PREMIER study: a multicenter, randomized, doubleblind clinical trial of combination therapy with adalimumab plus methotrexate versus methotrexate alone or adalimumab alone in patients with early, aggressive rheumatoid arthritis who had not had previo. Arthritis Rheum. 2006;54(1):26-37.

73. van der Heijde D, Klareskog L, Rodriguez-Valverde V, Codreanu C, Bolosiu H, Melo-Gomes J, et al. Comparison of etanercept and methotrexate, alone and combined, in the treatment of rheumatoid arthritis: two-year clinical 
and radiographic results from the TEMPO study, a double-blind, randomized trial. Arthritis Rheum. 2006;54(4):1063-74.

74. Hyrich KL, Watson KD, Silman AJ, Symmons DPM. Predictors of response to TNFi-alpha therapy among patients with rheumatoid arthritis: results from the British Society for Rheumatology biologics register. Rheumatology (Oxford). 2006:45(12):1558-65.

75. Edwards JCW, Szczepanski L, Szechinski J, Filipowicz-Sosnowska A, Emery P, Close DR, et al. Efficacy of B-cell-targeted therapy with rituximab in patients with rheumatoid arthritis. N Engl J Med. 2004;350(25):2572-81.

76. Emery P, Fleischmann RM, Doyle MK, Strusberg I, Durez P, Nash P, et al. Golimumab, a human anti-tumor necrosis factor monoclonal antibody, injected subcutaneously every 4 weeks in patients with active rheumatoid arthritis who had never taken methotrexate: 1-year and 2-year clinical, radiologic, and physical function findings. Arthritis Care Res (Hoboken). 2013;65(11):1732-42.

77. Burmester GR, Rigby WF, van Vollenhoven RF, Kay J, Rubbert-Roth A, Kelman $A$, et al. Tocilizumab in early progressive rheumatoid arthritis: FUNCTION, a randomised controlled trial. Ann Rheum Dis. 2016;75(6): 1081-91.

78. Burmester GR, Rigby WF, van Vollenhoven RF, Kay J, Rubbert-Roth A, Kelman A, et al. Tocilizumab in combination therapy and monotherapy versus methotrexate in methotrexate-naive patients with early rheumatoid arthritis: clinical and radiographic outcomes from a randomized, placebocontrolled trial. Arthritis Rheum [Internet]. 2013;65:S1182-3.

79. Kaneko Y, Atsumi T, Tanaka Y, Inoo M, Kobayashi-Haraoka H, Amano K, et al. Comparison of adding tocilizumab to methotrexate with switching to tocilizumab in patients with rheumatoid arthritis with inadequate response to methotrexate: 52-week results from a prospective, randomised, controlled study (SURPRISE study). Ann Rheum Dis. 2016;75(11):1917-23.

80. Chatzidionysiou K, Lie E, Nasonov E, Lukina G, Hetland ML, Tarp U, et al. Effectiveness of disease-modifying antirheumatic drug co-therapy with methotrexate and leflunomide in rituximab-treated rheumatoid arthritis patients: results of a 1-year follow-up study from the CERERRA collaboration. Ann Rheum Dis. 2012;71(3):374-7.

81. Wendler J, Sørensen H, Tony H, Richter C, Krause A, Rubbert-Roth A, Effectiveness BMBG. Safety of rituximab (RTX) monotherapy compared to RTX combination therapy with methotrexate or leflunomide in the German RTX-treatment of active rheumatoid arthritis in daily practice trial. Ann Rheum Dis. 2009;68:76.

82. Lee YH, Bae S-C. Comparative efficacy and safety of tocilizumab, rituximab, abatacept and tofacitinib in patients with active rheumatoid arthritis that inadequately responds to tumor necrosis factor inhibitors: a Bayesian network meta-analysis of randomized controlled tri. Int J Rheum Dis. 2016;19(11):1103-11.

83. Smolen JS, Burmester G-R, Combe B, Curtis JR, Hall S, Haraoui B, et al. Headto-head comparison of certolizumab pegol versus adalimumab in rheumatoid arthritis: 2-year efficacy and safety results from the randomised EXXELERATE study. Lancet (London, England). 2016;388(10061):2763-74.

84. Smolen JS, Kay J, Doyle MK, Landewe R, Matteson EL, Wollenhaupt J, et al. Golimumab in patients with active rheumatoid arthritis after treatment with tumour necrosis factor alpha inhibitors (GO-AFTER study): a multicentre, randomised, double-blind, placebo-controlled, phase III trial. Lancet (London, England). 2009;374(9685):210-21.

85. Mease PJ, Cohen S, Gaylis NB, Chubick A, Kaell AT, Greenwald M, et al. Efficacy and safety of retreatment in patients with rheumatoid arthritis with previous inadequate response to tumor necrosis factor inhibitors: results from the SUNRISE trial. J Rheumatol. 2010;37(5):917-27.

86. Gonzalez-Vacarezza N, Aleman A, Gonzalez G, Perez A. Rituximab and tocilizumab for the treatment of rheumatoid arthritis. Int J Technol Assess Health Care. 2014;30(3):282-8.

87. Kim H-L, Lee M-Y, Park S-Y, Park S-K, Byun J-H, Kwon S, et al. Comparative effectiveness of cycling of tumor necrosis factor-alpha (TNF-alpha) inhibitors versus switching to non-TNF biologics in rheumatoid arthritis patients with inadequate response to TNF-alpha inhibitor using a Bayesian approach. Arch Pharm Res. 2014;37(5):662-70.

88. Schoels M, Aletaha D, Smolen JS, Wong JB. Comparative effectiveness and safety of biological treatment options after tumour necrosis factor alpha inhibitor failure in rheumatoid arthritis: systematic review and indirect pairwise meta-analysis. Ann Rheum Dis England. 2012;71(8):1303-8.

89. Joensuu JT, Huoponen S, Aaltonen KJ, Konttinen YT, Nordstrom D, Blom M. The cost-effectiveness of biologics for the treatment of rheumatoid arthritis: a systematic review. PLoS One. 2015;10(3):e0119683.
90. Gottenberg J-E, Brocq O, Perdriger A, Lassoued S, Berthelot J-M, Wendling $D$, et al. Non-TNF-targeted biologic vs a second TNFi drug to treat rheumatoid arthritis in patients with insufficient response to a first TNFi drug: a randomized clinical trial. JAMA. 2016;316(11):1172-80.

91. Malottki K, Barton P, Tsourapas A, Uthman AO, Liu Z, Routh K, et al. Adalimumab, etanercept, infliximab, rituximab and abatacept for the treatment of rheumatoid arthritis after the failure of a tumour necrosis factor inhibitor: a systematic review and economic evaluation. Health Technol Assess. 2011;15(14):1-278.

92. Kremer J, Li Z-G, Hall S, Fleischmann R, Genovese M, Martin-Mola E, et al. Tofacitinib in combination with nonbiologic disease-modifying antirheumatic drugs in patients with active rheumatoid arthritis: a randomized trial. Ann Intern Med. 2013;159(4):253-61.

93. van Vollenhoven RF, Fleischmann R, Cohen S, Lee EB, Garcia Meijide JA, Wagner $\mathrm{S}$, et al. Tofacitinib or adalimumab versus placebo in rheumatoid arthritis. N Engl J Med. 2012;367(6):508-19.

94. Kremer JM, Cohen S, Wilkinson BE, Connell CA, French JL, Gomez-Reino J, Gruben D, Kanik KS, Krishnaswami S, Pascual-Ramos V, Wallenstein G, Zwillich SH. A phase llb dose-ranging study of the oral JAK inhibitor tofacitinib $(C P-690,550)$ versus placebo in combination with background methotrexate in patients with active rheumatoid arthritis and an inadequate response to methotrexate alone. Arthritis Rheum. 2012;64(4):970-81.

95. Singh JA, Hossain A, Tanjong Ghogomu E, Mudano AS, Tugwell P, Wells GA. Biologic or tofacitinib monotherapy for rheumatoid arthritis in people with traditional disease-modifying anti-rheumatic drug (DMARD) failure: a Cochrane systematic review and network meta-analysis (NMA). Cochrane Database Syst Rev. 2016;11:CD012437.

96. Singh JA, Hossain A, Tanjong Ghogomu E, Mudano AS, Maxwell L, Buchbinder $\mathrm{R}$, et al. Biologics or tofacitinib for people with rheumatoid arthritis unsuccessfully treated with biologics: a systematic review and network meta-analysis. Cochrane Database Syst Rev. 2017;3:CD012591.

97. Burmester GR, Blanco R, Charles-Schoeman C, Wollenhaupt J, Zerbini C, Benda B, et al. Tofacitinib (CP-690,550) in combination with methotrexate in patients with active rheumatoid arthritis with an inadequate response to tumour necrosis factor inhibitors: a randomised phase 3 trial. Lancet (London, England). 2013;381(9865):451-60.

98. Montecucco C, Todoerti M, Sakellariou G, Scire CA, Caporali R. Low-dose oral prednisone improves clinical and ultrasonographic remission rates in early rheumatoid arthritis: results of a 12-month open-label randomised study. Arthritis Res Ther. 2012;14(3):R112.

99. Choy EHS, Smith CM, Farewell V, Walker D, Hassell A, Chau L, et al. Factorial randomised controlled trial of glucocorticoids and combination disease modifying drugs in early rheumatoid arthritis. Ann Rheum Dis. 2008;67(5):656-63.

100. Kirwan JR, Bijlsma JWJ, Boers M, Shea BJ. Effects of glucocorticoids on radiological progression in rheumatoid arthritis. Cochrane Database Syst Rev. 2007;1:CD006356.

101. van der Goes MC, Jacobs JW, Boers M, Kirwan JR, Hafström I, Svensson B, et al. AT0217 long term effects of glucocorticoid therapy on radiological progression of joint damage in rheumatoid arthritis: an individual patient Meta-analysis. Ann Rheum Dis. 2015;74:736.

102. Kume K, Amano K, Yamada S, Kanazawa T, Ohta H. Hatta 2K. THU0211 combination of intra-articular steroid injection and Etanercept more effective than Etanercept in rapid radiographic progression patients with rheumatoid arthritis: a randomized, open label, $\mathrm{X}$ ray reader blinded study. Ann Rheum Dis. 2013;72:A235-6.

103. Bakker MF, Jacobs JWG, Welsing PMJ, Verstappen SMM, Tekstra J, Ton E, et al. Low-dose prednisone inclusion in a methotrexate-based, tight control strategy for early rheumatoid arthritis: a randomized trial. Ann Intern Med. 2012;156(5):329-39.

104. Fautrel B, Pham T, Alfaiate T, Gandjbakhch F, Foltz V, Morel J, et al. Stepdown strategy of spacing TNF-blocker injections for established rheumatoid arthritis in remission: results of the multicentre non-inferiority randomised open-label controlled trial STRASS: spacing of TNF-blocker injections in rheumatoid ArthritiS St. Ann Rheum Dis. 2016;75(1):59-67.

105. Haschka J, Englbrecht M, Hueber AJ, Manger B, Kleyer A, Reiser M, et al. Relapse rates in patients with rheumatoid arthritis in stable remission tapering or stopping antirheumatic therapy: interim results from the prospective randomised controlled RETRO study. Ann Rheum Dis. 2016;75(1):45-51.

106. van Herwaarden N, van der Maas A, Minten MJM, van den Hoogen FHJ, Kievit W, van Vollenhoven RF, et al. Disease activity guided dose reduction and withdrawal of adalimumab or etanercept compared with usual care in 
rheumatoid arthritis: open label, randomised controlled, non-inferiority trial. BMJ. 2015;350:h1389.

107. Smolen JS, Nash P, Durez P, Hall S, llivanova E, Irazoque-Palazuelos F, et al. Maintenance, reduction, or withdrawal of etanercept after treatment with etanercept and methotrexate in patients with moderate rheumatoid arthritis (PRESERVE): a randomised controlled trial. Lancet (London, England). 2013;381 (9870):918-29.

108. Kuijper TM, Lamers-Karnebeek FBG, Jacobs JWG, Hazes JMW, Luime JJ. Flare rate in patients with rheumatoid arthritis in low disease activity or remission when tapering or stopping synthetic or biologic DMARD: a systematic review. J Rheumatol. 2015;42(11):2012-22.

109. Jiang M, Ren F, Zheng Y, Yan R, Huang W, Xia N, et al. Efficacy and safety of down-titration versus continuation strategies of biological diseasemodifying anti-rheumatic drugs in patients with rheumatoid arthritis with low disease activity or in remission: a systematic review and meta-analysis. Clin Exp Rheumatol. 2017;35(1):152-60.

110. Emery P, Hammoudeh M, FitzGerald O, Combe B, Martin-Mola E, Buch MH, et al. Sustained remission with etanercept tapering in early rheumatoid arthritis. N Engl J Med. 2014;371(19):1781-92.

111. Smolen JS, Emery P, Fleischmann R, van Vollenhoven RF, Pavelka K, Durez P, et al. Adjustment of therapy in rheumatoid arthritis on the basis of achievement of stable low disease activity with adalimumab plus methotrexate or methotrexate alone: the randomised controlled OPTIMA trial. Lancet (London, England). 2014;383(9914):321-32.

112. Tanaka Y, Takeuchi T, Mimori T, Saito K, Nawata M, Kameda H, et al. Discontinuation of infliximab after attaining low disease activity in patients with rheumatoid arthritis: RRR (remission induction by Remicade in RA) study. Ann Rheum Dis England. 2010;69(7):1286-91.

113. Smolen JS, Breedveld FC, Burmester GR, Bykerk V, Dougados M, Emery P, et al. Treating rheumatoid arthritis to target: 2014 update of the recommendations of an international task force. Ann Rheum Dis. 2016;75(1):3-15.

114. Kievit W, van Herwaarden N, van den Hoogen FH, van Vollenhoven RF, Bijlsma JW, van den Bemt BJ, et al. Disease activity-guided dose optimisation of adalimumab and etanercept is a cost-effective strategy compared with non-tapering tight control rheumatoid arthritis care: analyses of the DRESS study. Ann Rheum Dis. 2016;75(11):1939-44.

115. van Herwaarden N, den Broeder AA, Jacobs W, van der Maas A, Bijlsma JWJ, van Vollenhoven RF, et al. Down-titration and discontinuation strategies of tumor necrosis factor-blocking agents for rheumatoid arthritis in patients with low disease activity. Cochrane database Syst Rev. 2014;9:CD010455.

116. Schett G, Emery P, Tanaka Y, Burmester G, Pisetsky DS, Naredo E, et al. Tapering biologic and conventional DMARD therapy in rheumatoid arthritis: current evidence and future directions. Ann Rheum Dis England. 2016;75(8):1428-37.

117. Kobelt $\mathrm{G}$. Treating to target with etanercept in rheumatoid arthritis: costeffectiveness of dose reductions when remission is achieved. Value Heal 」 Int Soc Pharmacoeconomics Outcomes Res. 2014;17(5):537-44.

118. Felson DT, Smolen JS, Wells G, Zhang B, van Tuyl LHD, Funovits J, et al. American College of Rheumatology/European league against rheumatism provisional definition of remission in rheumatoid arthritis for clinical trials. Arthritis Rheum. 2011;63(3):573-86.

119. Anderson J, Caplan L, Yazdany J, Robbins ML, Neogi T, Michaud K, et al. Rheumatoid arthritis disease activity measures: American College of Rheumatology recommendations for use in clinical practice. Arthritis Care Res (Hoboken). 2012;64(5):640-7.

120. Singh JA, Cameron DR. Summary of AHRQ's comparative effectiveness review of drug therapy for rheumatoid arthritis (RA) in adults-an update. J Manag Care Pharm. 2012;18(4 Supp C):S1-18.

121. Ding $C-Z$, Yao Y, Feng $X-B$, Fang Y, Zhao C, Wang Y. Clinical analysis of chinese patients with rheumatoid arthritis treated with leflunomide and methotrexate combined with different dosages of glucocorticoid. Curr Ther Res Clin Exp. 2012;73(4-5):123-33.

122. Colebatch AN, Marks JL, Edwards CJ. Safety of non-steroidal anti-inflammatory drugs, including aspirin and paracetamol (acetaminophen) in people receiving methotrexate for inflammatory arthritis (rheumatoid arthritis, ankylosing spondylitis, psoriatic arthritis, other spondyloarthritis). Cochrane Database Syst Rev. 2011;11:CD008872

123. Chen Y-F, Jobanputra P, Barton P, Bryan S, Fry-Smith A, Harris G, et al. Cyclooxygenase-2 selective non-steroidal anti-inflammatory drugs (etodolac, meloxicam, celecoxib, rofecoxib, etoricoxib, valdecoxib and lumiracoxib) for osteoarthritis and rheumatoid arthritis: a systematic review and economic evaluation. Health Technol Assess. 2008;12(11):1-278, iii.

124. Bickham K, Kivitz AJ, Mehta A, Frontera N, Shah S, Stryszak P, et al. Evaluation of two doses of etoricoxib, a COX-2 selective non-steroidal anti-inflammatory drug (NSAID), in the treatment of rheumatoid arthritis in a double-blind, randomized controlled trial. BMC Musculoskelet Disord. 2016;17:331.

125. Kvien TK, Greenwald M, Peloso PM, Wang H, Mehta A, Gammaitoni A. Do COX-2 inhibitors provide additional pain relief and anti-inflammatory effects in patients with rheumatoid arthritis who are on biological diseasemodifying anti-rheumatic drugs and/or corticosteroids? Post-hoc analyses from a randomized clinical trial. BMC Musculoskelet Disord. 2015;16:26.

126. van Walsem A, Pandhi S, Nixon RM, Guyot P, Karabis A, Moore RA. Relative benefit-risk comparing diclofenac to other traditional non-steroidal antiinflammatory drugs and cyclooxygenase-2 inhibitors in patients with osteoarthritis or rheumatoid arthritis: a network meta-analysis. Arthritis Res Ther. 2015;17:66

127. Adams K, Bombardier C, van der Heijde D. Safety and efficacy of ondemand versus continuous use of nonsteroidal antiinflammatory drugs in patients with inflammatory arthritis: a systematic literature review. J Rheumatol Suppl. 2012;90:56-8.

128. American College of Rheumatology Subcommittee on Rheumatoid Arthritis Guidelines. Guidelines for the management of rheumatoid arthritis: 2002 Update. Arthritis Rheum. 2002;46(2):328-46.

129. Katchamart W, Johnson S, Lin H-JL, Phumethum V, Salliot C, Bombardier C. Predictors for remission in rheumatoid arthritis patients: a systematic review. Arthritis Care Res (Hoboken). 2010;62(8):1128-43.

130. Ferraz-Amaro I, Machin S, Carmona L, Gonzalez-Alvaro I, Diaz-Gonzalez F. Pattern of use and safety of non-steroidal anti-inflammatory drugs in rheumatoid arthritis patients. A prospective analysis from clinical practice. Reumatol Clin. 2009;5(6):252-8.

131. Dougados M, Kissel K, Sheeran T, Tak PP, Conaghan PG, Mola EM, et al. Adding tocilizumab or switching to tocilizumab monotherapy in methotrexate inadequate responders: 24-week symptomatic and structural results of a 2-year randomised controlled strategy trial in rheumatoid arthritis (ACT-RAY). Ann Rheum Dis. 2013;72(1):43-50.

132. Buch MH, Smolen JS, Betteridge N, Breedveld FC, Burmester G, Dorner T, et al. Updated consensus statement on the use of rituximab in patients with rheumatoid arthritis. Ann Rheum Dis. 2011;70(6):909-20.

133. van Vollenhoven RF, Ostergaard M, Leirisalo-Repo M, Uhlig T, Jansson M, Larsson $\mathrm{E}$, et al. Full dose, reduced dose or discontinuation of etanercept in rheumatoid arthritis. Ann Rheum Dis. 2016;75(1):52-8.

134. Komaki Y, Yamada A, Komaki F, Kudaravalli P, Micic D, Ido A, et al. Efficacy, safety and pharmacokinetics of biosimilars of anti-tumor necrosis factoralpha agents in rheumatic diseases; a systematic review and meta-analysis. $J$ Autoimmun. 2017;79:4-16.

135. Yoo DH, Racewicz A, Brzezicki J, Yatsyshyn R, Arteaga ET, Baranauskaite A, et al. A phase III randomized study to evaluate the efficacy and safety of CT-P13 compared with reference infliximab in patients with active rheumatoid arthritis: 54-week results from the PLANETRA study. Arthritis Res Ther. 2016;18:82.

136. Yoo DH, Suh CH, Shim SC, Jeka S, Molina FFC, Hrycaj P, et al. Efficacy, Safety and Pharmacokinetics of Up to Two Courses of the Rituximab Biosimilar CTP10 Versus Innovator Rituximab in Patients with Rheumatoid Arthritis: Results up to Week 72 of a Phase I Randomized Controlled Trial. BioDrugs. 2017;31(4):357-367.

137. Cohen S, Emery P, Greenwald M, Yin D, Becker J-C, Melia LA, et al. A phase I pharmacokinetics trial comparing PF-05280586 (a potential biosimilar) and rituximab in patients with active rheumatoid arthritis. Br I Clin Pharmacol. 2016;82(1):129-38.

138. Eremeeva A, Chernyaeva E, Ivanov R, Nasonov E, Knyazeva L. FRI0224 comparison of efficacy and safety of rituximab biosimilar, BCD-020, and innovator rituximab in patients with active rheumatoid arthritis refractory to TNFA inhibitors. Ann Rheum Dis. 2016;75:513-4.

139. Jacobs I, Petersel D, Isakov L, Lula S, Lea Sewell K. Biosimilars for the treatment of chronic inflammatory diseases: a systematic review of published evidence. BioDrugs. 2016;30(6):525-70.

140. Chingcuanco F, Segal JB, Kim SC, Alexander GC. Bioequivalence of biosimilar tumor necrosis factor-alpha inhibitors compared with their reference biologics: a systematic review. Ann Intern Med. 2016;165(8):565-74 
141. Tothfalusi L, Endrenyi L, Chow S-C. Statistical and regulatory considerations in assessments of interchangeability of biological drug products. Eur J Health Econ. 2014;15(Suppl 1):S5-11.

142. Aletaha D, Smolen JS. The Simplified Disease Activity Index (SDAI) and Clinical Disease Activity Index (CDAl) to monitor patients in standard clinical care. Best Pract Res Clin Rheumatol. 2007;21(4):663-75.

143. Aletaha D, Funovits J, Ward MM, Smolen JS, Kvien TK. Perception of improvement in patients with rheumatoid arthritis varies with disease activity levels at baseline. Arthritis Rheum. 2009;61(3):313-20.

144. Smolen JS, Aletaha D. Scores for all seasons: SDAI and CDAI. Clin Exp Rheumatol. 2014:32(5 Suppl 85):S-75-9.

Ready to submit your research? Choose BMC and benefit from:

- fast, convenient online submission

- thorough peer review by experienced researchers in your field

- rapid publication on acceptance

- support for research data, including large and complex data types

- gold Open Access which fosters wider collaboration and increased citations

- maximum visibility for your research: over $100 \mathrm{M}$ website views per year

At BMC, research is always in progress.

Learn more biomedcentral.com/submissions 